\title{
Investigating the Nexus among Sulfur Dioxide Emission, Energy Consumption and Economic Growth: Empirical Evidence from Pakistan
}

\section{Khuda Bakhsh}

COMSATS University Islamabad

\section{Tanzila Akmal}

University of Agriculture Faisalabad

\section{Tauqeer Ahmad}

COMSATS University Islamabad

Qasir Abbas ( $\nabla$ qaisarabbas@uaf.edu.pk)

University of Agriculture Faisalabad https://orcid.org/0000-0001-7442-2642

\section{Research Article}

Keywords: SO2 emission, Energy consumption, Economic growth, FDI, Pakistan

Posted Date: May 24th, 2021

DOI: https://doi.org/10.21203/rs.3.rs-404972/v1

License: (a) (i) This work is licensed under a Creative Commons Attribution 4.0 International License. Read Full License

Version of Record: A version of this preprint was published at Environmental Science and Pollution Research on September 1st, 2021. See the published version at https://doi.org/10.1007/s11356-02115898-9. 


\title{
Investigating the Nexus among Sulfur Dioxide Emission, Energy Consumption and
} Economic Growth: Empirical Evidence from Pakistan

Khuda Bakhsh, Department of Management Sciences, COMSATS University Islamabad, Vehari Campus, Pakistan Email: kbakhsh@ cuivehari.edu.pk 5

Tanzila Akmal, Institute of Agricultural and Resource Economics, University of

Agriculture, Faisalabad-Pakistan Email: tanzilaakmal143@gmail.com

Tauqeer Ahmad, Department of Management Sciences, COMSATS University Islamabad, Vehari Campus, Pakistan Email: tauqeerahmad@ ciitvehari.edu.pk

Qasir Abbas, Institute of Agricultural and Resource Economics, University of Agriculture, Faisalabad-Pakistan Email: qaisarabbas@uaf.edu.pk

Corresponding authors: Qasir Abbas, Email address. qaisarabbas@uaf.edu.pk

\begin{abstract}
Developing countries like Pakistan majorly depends on fossil fuels for achieving higher economic growth but have sloppy environmental rules and regulations in order to attract foreign direct investment (FDI). As a result, energy consumption is considered as the primary cause of environmental degradation. Besides $\mathrm{CO}_{2}$ emission, environmental degradation is also associated with emission of sulfur dioxide $\left(\mathrm{SO}_{2}\right)$. The purpose of this study was to investigate the relationship among $\mathrm{SO}_{2}$ emissions, energy consumption, economic growth and FDI in Pakistan. By applying the 3SLS method study has estimated the scale effect, composition effect and technique effect. The scale effect and technique effect findings indicated that capital stock, FDI, and $\mathrm{SO}_{2}$ emissions all had a significant impact on GDP. When the capital accumulation effects of FDI were considered, the
\end{abstract}


27 relationship between FDI and stock of capital was found to be positive. According to the 28 technique effect results, FDI, population density, and energy consumption were all 29 significantly related to $\mathrm{SO}_{2}$ emissions. The study came to a conclusion with significant 30 policy implications.

31 Keywords: $\mathrm{SO}_{2}$ emission; Energy consumption; Economic growth; FDI; Pakistan 


\section{Introduction}

34 Rapid economic growth in developing countries like China, India and Pakistan has led to increased energy consumption. Developing countries heavily depend on fossil fuels for energy generation and consumption. The massive use of the energy especially from fossil

37 fuels causes severe environmental degradation. Emitters such as $\mathrm{CO} 2, \mathrm{SO} 2$ and 38 particulate matter from energy consumption lead to air pollution. Although other factors 39 also contribute in pollution emission, fossil fuel consumption causes the larger amount of 40 pollution emissions. Yilanci et al. (2020) assert that long-term impact of energy 41 consumption leads to pollution emission. Literature showing the role of energy 42 consumption in CO2 emission is rich and recent (Bakhsh et al., 2017, Guzel and Okumus, 43 2020, Salahuddin et al., 2020, Udenba et al., 2020). Considering SO2 emission, it 44 depends on the sulfur content of the fossil fuels, in addition to the sectoral processes 45 leading to pollutant emission. SO2 oxidizes in the atmosphere to form aerosol thereby 46 influencing climate.

47 Major sources of SO2 emission are energy, transportation, industries, agriculture, forest 48 and livestock. Fig. 1 shows different sources of SO2 emission. Electric utilities including 49 electric power plants and refineries are the major sources of SO2 emission. Point sources 50 excluding electric utilities are vehicles operating on roads, highways and streets. These 51 are among the second major sources of SO2 emission. Residential wood burning, 52 gasoline service stations, dry cleaners, wildfires and agriculture tilling are among the 53 non-point sources of SO2 emission. Non-road sources of So2 emission include lawn and 54 garden equipment, aircrafts, locomotives, construction equipment and recreational 55 equipment.

56 The main economic source of $\mathrm{SO} 2$ emission is the industrial sector as it consumers a 57 larger quantity of energy sources. This sector highly relies on the consumption of fossil 58 fuels in developing countries including Pakistan. Further, industrial processes containing 59 sulfur such as electricity generation from oil, gas and coal cause SO2 emission. Thus 60 industrial sector is highly related to $\mathrm{SO} 2$ emission to the environment in Pakistan and 61 other developing countries. Yang and Shan (2019) argue that industrialization, economic 62 scale and energy consumption effects are major contributing factors of SO2 emission 
63 developing countries are facing challenge of increasing economic growth and reducing 64 pollutant emissions to realize sustainable economic development with clean environment and prosperous economy. Increasing renewable energy consumption and energy efficiency can reduce pollution emission. Contrary to renewable energy consumption, non-renewable energy consumptions lead to environmental degradation (Nathaniel et al., 219; Hu et al., 2019; Zafar et al., 2019; Destek and Sinha, 2020). Technology, energy mix, sulfur efficiency, industrial structure and energy efficiency effects are associated with a dwindling SO2 emission (Yang and Shan, 2019). Energy prices are also important in mitigating pollutant emissions (Hanif et al., 2019, Ngugen et al., 2020). Stringent energy policy with strong control on energy prices can reduce energy consumption, 73 increase energy efficiency and decrease pollutant emissions.

74 The role of foreign direct investment inflows in developing countries is of paramount 75 importance in increasing economic growth. There is rich literature examining relationship 76 between economic growth and FDI (see Anwar and Nguyen, 2010, Bakhsh et al., 2017, 77 Nadeem et al., 2020, Tsang and Yip, 2007). Shahbaz et al. (2018) and Hanif et al. (2019) 78 find huge contribution of FDI to economic growth in the host countries. Increasing 79 economic growth happens at the cost of environmental pollution. Many studies show a 80 positive relationship between economic growth and SO2 emission (Coggin, 2019, Hu et 81 al., 2019, Nadeem et al., 2020, Ramakrishnan et al., 2016, Wu, 2019). Ru et al. (2018) 82 and Wang et al. (2016) argue that there exists environmental Kuznet Curve (EKC) pattern 83 of relationship between economic growth and SO2 emission. This implies that SO2 84 emission increases with an increase in economic growth, reaches a maximum point and 85 then pollution emission starts declining with further economic progression.

86 Developing countries relax environmental rules and regulations to attract FDI inflows in 87 order to boost economic growth. Most importantly, FDI inflows are made in energy and 88 industrial sectors using natural resources namely oil, gas and coal. Hassaballa (2014) 89 shows bidirectional causality between FDI and energy consumption in the developing 90 nations. Resultantly, FDI has positive impact on SO2 emission in the host country (Zhu et 91 al., 2017). Thus FDI is related to pollution emissions thereby adversely affecting 92 environment (Omri et al., 2014; Tang and Tan, 2015; Shahbaz et al., 2015). However, 
93 Nadeem et al. (2020) find a negative long-term relationship between FDI and SO2 94 emission. This happens because pollutant emission rises with the progression of the economy, reaches a maximum point and then starts declining with further economic growth (Shahbaz and Sinha, 2019, Shahbaz et al., 2019). In addition to adverse impacts,

97 FDI inflows are also considered to have an important contribution in promoting better environmental awareness and environmental friendly technology in the developing countries (Zeng and Easten, 2012).

100 The relationship between FDIand pollution emission through an increase in income or energy consumption in the existing literature is still debatable because of mixed findings with regards to directionality (, Saboori et al., 2012,Omri and Kahouli, 2014; Shahbaz et al. 2015). There are some studies showing unidirectional relationship between FDI and pollution emission (Jaunky, 2010, Nasir and Rehman, 2011), others find bidirectional relationship (Halicioglu, 2009, Soytas and Sari, 2009) and there are some studies showing no relationship (Richmond and Kaufmann, 2006).and Zhang (2011) and Apergis Payne (2009) show mixed results of relationship between carbon emissions and income level of countries.Inconclusive relationship between FDI, pollutant emission and economic growth can be because of regional differences in environmental regulation, given the different sources, processes and economic factors. Zho et al. (2017) asserted that environmental regulation and land use are significant factors on the spatial pattern of SO2 emission. Thus the effects of FDI on pollutant emission can be heterogeneous across countries. Pakistan is a developing country and it has diverse customized energy sources, processes, environmental regulation and economic conditions compared to other developed countries. Therefore, SO2 emission can have distinct emission trajectories. Further, industrial sector is considered the main economic source of SO2 emission as it consumes electricity $25 \%$, oil $19 \%$ and gas $8 \%$. Contribution of industrial sector in gross domestic product is $20.19 \%$ (GoP, 2018). CO2 and SO2 are among the major pollutants emitted from industrial processes and other economic activities.SO2 emission deteriorates ambient environment quality causing greater threats to human health whereas $\mathrm{CO} 2$ emission causes global warming, in addition to threatening human health.Thus it is imperative to understand the economic growth, energy consumption and SO2 emission nexus at country level. Nordhaus (2010) and Stern and van Dijk (2017) maintain that it is 
124 the useful way to examine the emissions associated with social and economic 125 development.

126 This study has several departures from the earlier work on FDI, economic growth and 127 pollution emission. First, we look into $\mathrm{SO}_{2}$ emission instead of $\mathrm{CO}_{2}$ because of ambient 128 effects of $\mathrm{SO}_{2}$ emission. We used $\mathrm{SO} 2$ for two main reasons. Firstly, there is direct link 129 between SO2 emission and industrial output. Cherniwachan (2012) asserted that 1\% 130 increase in industrial share of output leads to $11.8 \%$ increase in per capita SO2 emission. 131 Secondly, the effects of SO2 emission are ambient rather than global. Second departure 132 from the literature is that we employ three stage least square (3SLS) method which is 133 conceptually stronger and empirically robust, besides being more appropriate to find out 134 trilateral nexus ofFDI, environmental pollution and economic growth. Many studies 135 relating to Pakistan determined relation between FDI and economic growth but very few 136 studies estimated the relation between FDI, economic growth and environmental 137 pollution (Mahmood and Chaudhry, 2012; Bakhsh et al., 2017; Yasmeen et al., 2019, 138 Wang et al., 2019). However, we find that these studies don't consider the mechanisms 139 through which foreign investment impacts environmental pollution particularly $\mathrm{SO} 2$ 140 emission. SO2 emission leading to environmental degradation causes huge losses to 141 human health and economic growth. The present study is contributing in the form of 142 considering the effects of FDIinflows on pollution emission, economic growth and capital 143 accumulation employing three stages least square (3SLS) method for solving 144 simultaneous equation system. This econometric method is considered more efficient 145 than two stage least square (2SLS) method because correlation between unobserved 146 disturbances across various equations in the system is allowed in 3SLS. Because of this 147 advantage, we employed 3SLS method in the present study. Findings of the 3SLS method 148 provide important policy insights for regulating FDI for environmental friendly and 149 efficient economic growth. This study also sheds light on the role of FDI in capital 150 accumulation. Thus, the country like Pakistan can gain the benefits of FDI in the 151 economic growth in the long-run while working on and designing environmental friendly 152 policies to pave the way for environmental sustainability. 
153 The remaining paper is arranged as follows: The first sub-section of section 154 2describesdata and sources. Second sub-section provides details on 3SLS method 155 employed in the present study. Sections 3 contain findings of 3SLS method including 156 technique effect, scale effect and composition effect findings of the study are compared 157 with the literature in this section as well. Section 4 gives conclusions and 158 recommendations.

\section{2. Material and Methods}

\section{$160 \quad 2.1$ Data and source}

161 There are different sources of SO2 emission in Pakistan. They include energy, industrial 162 processes, agriculture, land use change and forestry, and wastes. SO2 emission has 163 increased from 775 thousand tons in 1994 to 1041 thousand tons in 2015 recording an 164 increase of $34.3 \%$. Since industrial and agricultural sectors are the major consumers of 165 oil, gas and coal, these are the main economic sources of SO2 emission in the country. 166 Economic growth thus substantially depends on performance of agricultural and 167 industrial sectors. Further, economic growth is function of capital formation, employment 168 and FDI. FDI embodies some indirect benefits and costs in the form of bad 169 environmental quality (Lucas, 1988; Romer, 1990). In order to explore the empirical 170 relation among FDI, energy consumption, $\mathrm{SO}_{2}$ emission and economic growth, annual 171 data was used for the period of 1975 to 2015.We were interested to consider the 172 relationship between SO2 emission, energy consumption and economic growth at 173 different sector levels. However, the data on SO2 emission is not available on sector 174 levels from 2011 to onward. Therefore, we planned the study at country level. Table 1 175 provides information on definition of variables and sources of data. Different sources 176 were used to collect data on the real gross domestic product (US\$ million), gross fixed 177 capital formation (US million dollar), capital intensity, investment (US\$ million), 178 industrialization (\% of GDP), FDI (US\$ million) and population density (persons living 179 in one square kilometer). Data on energy (kt as energy use equivalent to oil) was taken 180 from World Development Indicators (WDI). Data on $\mathrm{SO}_{2}$ emissions (giga tons) was 181 taken from two sources. WDI was used to collect data from 1975-2010 whereas the 182 remaining data from 2011 to 2015 was obtained from GoP (2018a). Standard method was 
used to generate missing values of SO2 emission for some years. For smooth and easy interpretation of the results, log form of data was used in the estimation.

\subsection{Empirical Methods}

186 Copeland and Taylor (2003) suggest that emission can have three types of effects namely

187 scale effect, technique effect and composition effect. Scale effect refers gross domestic product whereas ratio of industrial output to gross domestic product is known as composition effect. Technique effect is defined as the ratio of pollution to industrial value added. In the present study, sulphur dioxide (SO2) is used as a pollutant. When we examine the scale effect, technique effect and composition effect, there is a problem of simultaneity. Hausman test was used to find simultaneity problem while rank and order conditions were used for identification problem. Because of the existence of correlation between unobserved disturbances across a simultaneous equations system as it is the case in the present study, 3SLS technique was employed to estimate environmental effects of FDI. Fig. 2 shows steps used in 3SLS empirical method. 3SLS technique has advantages over single equation estimates and 2SLS (see Bakhsh et al., 2017, Bao et al., 2010). Decomposition of pollution emission into three effects can be written as:

$$
\text { pol }=g d p+\text { tech }+\operatorname{comp}
$$

Eq. 1 is the identical equation showing pollution indicators resulting from FDI (Bakhsh et al., 2017, Bao et al. 2010). Sulfur dioxide (SO2) is taken as pollution indicator. SO2 is dependent variable in Eq. 1 whereas explanatory variables include scale effect, composition effect and technique effect.

A system of six equations is used to simultaneously estimate three effects of FDI on emissions and growth in Pakistan. The impact of FDI on the economic scale is measured by using Eq. 2(Bakhsh et al., 2017, Bao et al. 2010).

$$
g d p=\alpha_{0}+\alpha_{1} f d i+\alpha_{2} k+\alpha_{3} p o l u+\alpha_{4} p l_{t-1}+\alpha_{5} \text { time }+\varepsilon_{1}
$$

Here $g d p$ shows gross domestic product of Pakistan, FDI is shown by $f d i$, stock of capital is represented by $k$, andpolu is $\mathrm{SO} 2$ emission in Pakistan. $\alpha_{0 \text { to }} \alpha_{5}$ are parameters to be predictable. ${ }^{\varepsilon}$ is white noise error term. We expect a negative sign for coefficient of pollution emission variable because of its damaging effect. FDI is directly related to economic growth as indicated by Cole et al. (2011) whereas physical capital in the 
213 country also increases indirectly with an increase in FDI (Zhang et al., 2004). Eq. 3

214 shows estimation procedure of the indirect effect of FDI on financial advancement 215 (Bakhsh et al., 2017, Bao et al. 2010).

$216 k=d_{0}+d_{1} f d i+d_{2}\left(g d p_{t-1}\right)+d_{3}\left(g d p_{t-2}\right)+\alpha_{4} t i m e+\varepsilon_{2}$

217 One and two periods of lagged GDP values are used to measure the impact of economic 218 growth and environmental asymmetries on development. We employed Eq. 4 for 219 estimating technique effect (Bakhsh et al., 2017, Bao et al. 2010).

$$
\text { tech }=\beta_{0}+\beta_{1} f d i+\beta_{2} g d p+\beta_{3} p d+\beta_{4} e n g+\beta_{5} \text { time }+\varepsilon_{3}
$$

221 Here technique effect is shown by tech, $f d i$ shows FDI, $p d$ represents population 222 density, eng is energy consumed in Pakistan, time is time period as a proxy for 223 technology development in the country. $\beta_{0}$ to $\beta_{5}$ are parameters to be estimated. The 224 increase in per capita income is expected to increase economic activity, which in turn 225 leads to an increase in demand for a healthier environment. Further, an increase per capita income also implies allocation of resources for protecting the environment and abating pollution as indicated by Grossman and Kruger (1995) and Pao and Tsi (2010). Eq. 5 is used to estimate this type of the effect while considering composition effect (Bakhsh et al., 2017, Bao et al. 2010).

$$
\text { comp }=\delta_{0}+\delta_{1} f d i+\delta_{2} k / l+\delta_{3} g d p+\delta_{4} \text { time }+\varepsilon_{4}
$$

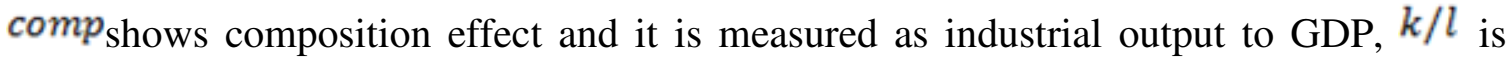
capital to labor ratio, $\delta_{0}$ to $\delta_{4}$ are parameters to be estimated. Higher physical capital stock increases industrial output, which leads to rising level of SO2 emission. The effect of GDP on dependent variable can be of two types. First it indicates higher level of industrialization in the country and second, it represents the increased demand for cleaner environment when per capita GDP rises due to industrialization.

237 Before taking decision about FDI inflows in any developing host country, the developed 238 countries consider time and country specific factors. Eq. 6is used to examine the factors 239 affecting FDI inflows in Pakistan (Bakhsh et al., 2017, Bao et al. 2010).

$240 \quad f d i=\gamma_{0}+\gamma_{1} f d i_{t-1}+\gamma_{2 i n d} d_{t-1}+\gamma_{3} i n v_{t-1}+\gamma_{4} p o l+\gamma_{5} t i m e+\varepsilon_{5}$

241 System of equations have endogeneity issue, thus we have taken one period lagged value 242 of FDI in the model to avoid endogeneity. We include domestic investment, 
243 industrialization and pollution emission level to see the effect of decision to invest in

244 Pakistan.

245 The above system of equations shows mechanisms by which FDI may have influence on

246 pollution emissions in the host nation. The direct effects of FDI on pollution emission can

247 be measured by the coefficients namely $d_{1}, \beta 1$ and $\delta 1$. FDI affects indirectly pollution

248 emissions through its effect on GDP when greenhouse gas emissions and industrial

249 composition vary with economic development. The indirect effect can be jointly

250 measured by $a 1$ and $\beta 5\left(\delta_{4}\right)$. In addition, the indirect impact of FDI on toxic greenhouse

251 gas emissions can be measured by the adverse effect on economic development, which

252 has effects on both the scale effect and the composition effect. Furthermore, feedback

253 implication of emissions ( $\mathrm{SO} 2$ in the present study) on economic growth is also 254 considered.

255 We also estimated the composite effect of foreign direct investment on the emission of 256 SO2 in Pakistan using methods used by Bao et al. (2010). The total effect of FDI on SO2 257 emission can be estimated using Eq. 7 as under:

$$
\frac{\partial p o l u}{\partial f d i}=\frac{\left(\beta_{1}+\delta_{1}+\delta_{2} d_{1}\right)+\left(1+\beta_{2}+\delta_{3}\right)\left(a_{1}+a_{2} d_{1}\right)}{1-\left(1+\beta_{2}+\delta_{3}\right) a_{4}}
$$

Scale effect is estimated using Eq. 8. All identities given in equation are defined earlier.

The technique effect is determined using Eq. 9 as under:

$$
\frac{\partial g d p}{\partial f d i}=\frac{\left(\beta_{1}+\delta_{1}+\delta_{2} d_{1}\right) a_{4}+\left(a_{1}+a_{2} d_{1}\right)}{1-\left(1+\beta_{2}+\delta_{3}\right) a_{4}}
$$

$$
\frac{\partial t e c h}{\partial f d i}=\beta_{1}+\frac{\left(\beta_{1}+\delta_{1}+\delta_{2} d_{1}\right) a 4+\left(a_{1}+a_{2} d_{1}\right)}{1-\left(1+\beta_{2}+\delta_{3}\right) a_{4}} \beta_{2}
$$

The composition effect of FDI on (SO2) emissions is appraised by using Eq. 10:

$$
\frac{\partial c o m p}{\partial f d i}=\frac{\left(d_{1}+d_{2} b_{1}\right)\left(1-a_{4}-a_{4} \beta_{2}\right)+\delta_{3}\left(a_{1}+a_{2} d_{1}\right)+\beta_{1} a_{4} \delta_{3}}{1-\left(1+\beta_{2}+\delta_{3}\right) a_{4}}
$$

265

$a_{1}, \beta_{1}$ and $\delta_{1}$ are the direct parameters of the scale, technique and composition effects of the

266 FDI respectively. Capital accumulation emphasizes the importance of FDI inflows in the 267 country. It is given by the coefficient of capital accumulations. Thus, capital 
accumulation accelerates economic activity through scale effect. The formula

$269 d_{1}\left(a_{2}+\delta_{2}\right)$ being measured indirect effect of capital accumulation of FDI in the country.

270 The technical and compositional effects are used to show the level of economic growth

271 and emissions of pollution. Scale effect is used to show the feedback impact of pollution

272 emissions on economic growth. The scale effect can have impact on technique effect and

273 composition effect $\left(\beta_{2}+\delta_{3}\right)$ and we can see the total feedback effect by the measure

$274 \beta_{2}\left(1+\beta_{2}+\delta_{3}\right)$. All notations used in the above equations are defined in Appendix A.

\section{3. Results and discussions}

276 Foreign direct investment is associated with toxic greenhouse gas emissions and 277 economic development in the host country. To examine these effects, we employed 278 3SLS. A system of six equations are considered in the present study, however, Eq. 1 is 279 identity equation, so it is not possible to estimate it directly. The remaining five equations 280 are measured to determine the impact of FDI on growth and emissions of SO2. Table 2 281 shows estimates of scale effect. We find that the coefficient of $(f d i)$ is negative and 282 statistically significant. Increased pollution in the country causes various environmental 283 and health hazards and erodes PakRs450 billion per year (GOP, 2014). Although all 284 economic sectors are recipient of FDI in Pakistan, major FDI inflow is recorded in industrial sector. Weak institutions and less political stability are some of the reasons for no or little control on pollution emission. The findings of the study vary considerably from those of the studies Shahbaz et al., 2018 and Hanif et al., 2019,) which show a positive impact of FDI on economic growth. However, Omri et al. (2014) found a bidirectional causal relationship between emissions, economic growth and FDI.

Pollution variable i.e. The emission of SO2 is an important factor in the growth of GDP and therefore is the key concern of the present study. Copeland and Taylor (2003) point out that pollution is important factor of production in the country, besides labor and capital. An increase in SO2 emission increases economic growth significantly. Pollution emission in developing countries including Pakistan is positively to with economic growth. Ample evidence of empirical work show that economic growth and greenhouse gas emissions are positively associated (Chaabouni, Zghidi and Mbrake, 2016; Ahmad and Du, 2017;Alvarado et al., 2018;Ma et al., 2016; Ali et al., 2019;Nadeem et al., 2020, 
Saidi and Mbarek, 2016, Wang et al., 2016). Lax environmental rules and regulations in Pakistan induces firms to emit pollutants in the environment. Capital $(k)$ is also statistically significant implying that it has positive relation with economic growth. Table 3 shows the estimates of capital accumulation effect of FDI in Pakistan. We observe a positive association between FDI and capital accumulation which is statistically significant. Bakhsh et al. (2017) also found similar relationship in their study. the present year. To consider this effect, we have taken lagged value of gross domestic product in the capital accumulation effect (see Eq. 3). We find that previous year economic growth is significant and negatively related with capital accumulation in Pakistan. To see the influence of FDI on economic growth, it is estimated by using Eq. 3, we find 0.1287 total scale effect of foreign direct investment while considering SO2 emission. This scale effect is larger than estimate of Bakhsh et al. (2017) for CO2 emission.

Results of technique effect for SO2 emission and FDI are given in Table 4. A positive and significant coefficient of FDI implies that FDI inflows in the country increase marginal pollution damage. Foreign investors don't use environmental friendly technology in the developing countries because they are more interested in low cost production benefits (Lan et al., 2012). Thus FDI causes a significant environmental degradation in the host countries due to lax environmental monitoring and regulations. Countries with slow rates of increasing consumption activities found moderate economic growth rates and emissions (Díaz and Cancelo, 2009, Luqman et al., 2019). Wang et al. (2016) argue that environmental degradation is related with positive association between high energy consumption and emissions. Population density has a strong and substantial effect on SO2 emissions. This significant positive relationship shows that a rise in population density also increases marginal environmental damage. Increased environmental damage associated with increasing population density warrants for pollution control measures to protect environment. Many studies also find this type of relationship (Doytch and Uctum, 2016, Zhang and Zhu, 2016). Gross domestic product $(g d p)$ is negatively related with marginal pollution damage. Yavuz (2014) finds a longterm reverse effect of economic growth on pollution emissions and suggests that the 
329 economic activity itself would contribute to a decrease in emissions from pollution.

330 Energy consumption is positively related with marginal environmental damage in the 331 present study. Alvarado et al. (2018) and Cherni and Jounini (2017) explains a rise in

332 fossil fuel consumption as being related to economic growth. Ample evidence shows an 333 increase in energy consumption leading to pollution emission (Zhu et al., 2016; Behera 334 and Dash, 2017,Baek, 2016, Tang and Tan, 2015). The use of fossil fuels is the primary 335 source of pollution emissions namely $\mathrm{SO} 2$ and $\mathrm{CO} 2$. Based on the above topic, FDI raises 336 pollution, demonstrating that the technological impact is incapable of regulating or 337 reducing industrial pollution emissions, like $\mathrm{SO} 2$ as foreign firms use obsolete 338 technologies in the manufacturing process due to weak environmental regulations. 339 Although environmental laws for preventing or reducing pollution emissions exist, these 340 laws are not implemented in true letter and spirit in order to attract FDI in the country. 341 All this would have a detrimental long-term impact on economic growth 342 (Jayanthakumaran et al., 2012).

343 Estimates of composition effects are reported in Table 5. Results show that a rise in FDI 344 and a contribution of industrial production in the economy has positive and statistically 345 significant impacts. The ratio of capital labor is an important compositional impact 346 indicator. Taking into account the $\mathrm{k} / 1$ coefficient, we find that this vector induces an rise 347 in the share of industrial production in the economy. It happens primarily because the 348 manufacturing sector produces more toxic contamination as a result of capital-intensive 349 products production (Antweiler et al., 2001)

350 Table 6 shows the estimates of determinants of FDI. Coefficient of investment implies 351 that more investment by public and private sectors attracts more investment, possibly due 352 to indication of conducive environment for production and cost advantages. Self353 accumulation effects of FDI are estimated by taking lagged value of FDI. Statistically 354 significant and positive coefficient shows that economic conditions of the country during 355 the previous years attracted more FDI. Low cost of production and slack environmental 356 standard operating procedures are the possible reasons.

357 Table 7 reports various effects of FDI on SO2 emission and these estimates are based on 358 Bao et al. (2010) formulae discussed in the previous section. We find a negative estimate 359 of total effect of FDI on SO2 emission in the country. In the present study, the scale 
effect of FDI is positive. It indicated that an increase in FDI is causing a rise in gross domestic product. Our finding is consistent with that of Bao et al. (2010), who also find negative relationships between environmental pollution and FDI. The country with lax environmental rules, regulations and management always exhibits negative technique effect even it is economically progressing (Mahmood and Chaudhary, 2012). However, indirect composition effect is positive, implying that FDI inclusively increase the increase the host country's share of industrial sector in GDP.

367 The present study has a few limitations. It considered data at country level to examine economic growth, energy consumption and SO2 emission. It would have been great if SO2 emission at different sector and or provincial level were considered. Since the data on SO2 emission at sectoral and provincial levels is not available, future research should consider this limitation when the data becomes available. This study is limited to only Pakistan. Expanding the study at South Asian level can yield interesting findings. Taking only SO2 emission is another limitation of the study. In future, all greenhouse gas emissions should be considered while examining the economic growth, SO2 emission and energy consumption nexus.

\section{Conclusions and policy implications}

377 Economic growth and FDI are significantly related in the host country. FDI increases 378 environmental pollution such as SO2 and CO2 emissions. The present study explored 379 relations of FDI, SO2 emission, energy use and economic growth using 3SLS in Pakistan. 380 Results of technique effect showed that SO2 emission and capital had positive effect on 381 gross domestic product whereas FDI was negatively related to economic growth. 382 Technique effect method showed that FDI, population density and energy consumption 383 are positively related with $\mathrm{SO} 2$ emission and gross domestic product is negatively 384 associated with SO2 emission. In composition effect, FDI is positively related with 385 industrial output. FDI in the previous years and investment by public and private sector in 386 the host country were significant factors of FDI inflows. However, we found the negative 387 impact of SO2 emission on FDI inflows in the present study.

388 In spite of environmental degradation linked with FDI inflows, the developing countries 389 provide various incentives including lax environmental rules to foreign investors for speeding economic growth, building capital stock and generating opportunities to the 
skilled and unskilled labor force. Findings of the study reveal that the recipient of FDI

392 should emphasize the impacts of FDI on environmental quality because degrading environment costs the economy in the long-run. The need is also to develop environmental friendly technology required during production processes. This necessitates the role of research and development activities to move in this direction.

Recent estimates showing annual loss of PakRs450 billion owing to environmental degradation sensitize policymakers and other concerned to recognize the importance of environmental concerns in Pakistan. Therefore, Pakistan has started taking strategic measures to control environmental degradation. Similarly private sector especially industrial sector has to play a crucial role in overcoming SO2 emission. Although regulatory bodies exist to monitor pollution emissions, there is still need to strengthen these institutions for effective implementation of environmental rules and regulations.

\section{References}

405 Ahmad, N., \& Du, L. (2017). Effects of energy production and CO2 emissions on economic growth in Iran: ARDL approach. Energy, 123, 521-537 https://doi.org/10.1016/j.energy.2017.01.144

Ali, R., Bakhsh, K. and Yasin, A.M. (2019). Impact of urbanization on CO2 emissions in emerging economy: Evidence from Pakistan. Sustainable Cities and Society, 48, 101553 https://doi.org/10.1016/j.scs.2019.101553

Alvarado, R., Ponce, P., Criollo, A., Córdova, K., \& Khan, M. K. (2018). Environmental degradation and real per capita output: New evidence at the global level grouping countries by income levels. Journal of Cleaner Production, 189, 13-20 https://doi.org/10.1016/j.jclepro.2018.04.064

Antweiler, W., Copeland, B. R., \& Taylor, M. S. (2001). Is free trade good for the environment? American Economic Review, 91, 877-908 https://doi.org/10.1257/aer.91.4.877 
418 Anwar, S., \& Nguyen, L. P. (2010). Foreign direct investment and economic growth in

419

420

421

422

423

424

425

426

427

428

429

430

431

432

433

434

435

436

437

438

439

440

Vietnam. Asia Pacific Business Review, 16, 183-202 https://doi.org/10.1080/10438590802511031

Apergis, N., \& Payne, J. E. (2009). CO2 emissions, energy usage, and output in Central America.

Energy

Policy,

$37(8)$,

3282-3286

https://doi.org/10.1016/j.enpol.2009.03.048

Baek, J. (2016). A new look at the FDI-income-energy-environment nexus: dynamic panel data analysis of ASEAN. Energy Policy, 91, 22-27 https://doi.org/10.1016/j.enpol.2015.12.045

Bakhsh, K., Rose, S., Ali, M. F., Ahmad, N., \& Shahbaz, M. (2017). Economic growth, CO2 emissions, renewable waste and FDI relation in Pakistan: New evidences from 3SLS. Journal of Environmental Management, 196, 627-632 https://doi.org/10.1016/j.jenvman.2017.03.029

Bao, Q., Chen, Y., \& Song, L. (2011). Foreign direct investment and environmental pollution in China: a simultaneous equations estimation. Environment and Development Economics, 16, 71-92 https://doi.org/10.1017/S1355770X10000380.

Behera, S. R., \& Dash, D. P. (2017). The effect of urbanization, energy consumption, and foreign direct investment on the carbon dioxide emission in the SSEA (South and Southeast Asian) region. Renewable and Sustainable Energy Reviews, 70, 96-106 https://doi.org/10.1017/S1355770X10000380

Chaabouni, S., Zghidi, N., \& Mbarek, M. B. (2016). On the causal dynamics between CO2 emissions, health expenditures and economic growth. Sustainable Cities and Society, 22, 184-191 https://doi.org/10.1016/j.scs.2016.02.001 
441 Cherni, A., \& Jouini, S. E. (2017). An ARDL approach to the CO2 emissions, renewable energy and economic growth nexus: Tunisian evidence. International Journal of https://doi.org/10.1016/j.ijhydene.2017.08.072 Working Paper 2019-1, Florence, SC.

447 Cole, M. A., Elliott, R. J., \& Zhang, J. (2011). Growth, foreign direct investment, and the environment: evidence from Chinese cities. Journal of Regional Science, 51, 121-

Copeland, B., \& Taylor, M. (2003). Trade and the Environment Princeton University 138 https://doi.org/10.1111/j.1467-9787.2010.00674.x Press Princeton: NJ.

Destek, M. A., \& Sinha, A. (2020). Renewable, non-renewable energy consumption, economic growth, trade openness and ecological footprint: Evidence from organisation for economic Co-operation and development countries. Journal of Cleaner Production, 242, 118537 https://doi.org/10.1016/j.jclepro.2019.118537

Díaz-Vázquez, M., \& Cancelo, M. T. (2009). Emisiones de CO2 y azufre y crecimiento económico:¿ Una curva de Kuznets ambiental? Regional and Sectoral Economic Studies, 9(2).

GOP.(2014). Highlights of the Economic Survey of Pakistan. Ministry of Finance, Government of Pakistan (GOP), Islamabad. (GOP), Islamabad. 
GoP. (2018a). Pakistan's Second National Commission on Climate Change to United Nations Framework Convention on Climate Change (UNFCCC). Ministry of Climate Change, Government of Pakistan (GOP), Islamabad.

Doytch, N., \& Uctum, M. (2016). Globalization and the environmental impact of sectoral FDI. Economic Systems, 40, 582-594 https://doi.org/10.1016/j.ecosys.2016.02.005

Grossman, G. M., \& Krueger, A. B. (1995). Economic growth and the environment. The Quarterly Journal of Economics, 110, 353-377 https://doi.org/10.2307/2118443.

Guzel, A. E., \& Okumus, İ. (2020). Revisiting the pollution haven hypothesis in ASEAN5 countries: new insights from panel data analysis. Environmental Science and Pollution Research,https://doi.org/10.1007/s11356-020-08317-y

Halicioglu, F. (2009). An econometric study of CO2 emissions, energy consumption, income and foreign trade in Turkey. Energy Policy, 37, 1156-1164 https://doi.org/10.1016/j.enpol.2008.11.012

Hanif, I., Raza, S. M. F., Gago-de-Santos, P., \& Abbas, Q. (2019). Fossil fuels, foreign direct investment, and economic growth have triggered $\mathrm{CO} 2$ emissions in emerging Asian economies: some empirical evidence. Energy, 171, 493501https://doi.org/10.1016/j.energy.2019.01.011

Hassaballa, H. (2014). Testing for Granger causality between energy use and foreign direct investment inflows in developing countries. Renewable and Sustainable Energy Reviews, 31, 417-426 https://doi.org/10.1016/j.rser.2013.12.011

Hu, B., Li, Z., \& Zhang, L. (2019). Long-run dynamics of sulphur dioxide emissions, economic growth, and energy efficiency in China. Journal of Cleaner Production, 227, 942-949 https://doi.org/10.1016/j.jclepro.2019.04.170 
486 Jaunky, V. C. (2011). The CO2 emissions-income nexus: evidence from rich countries. Energy Policy, 39, 1228-1240 https://doi.org/10.1016/j.enpol.2010.11.050

Jayanthakumaran, K., Verma, R., \& Liu, Y. (2012). CO2 emissions, energy consumption, trade and income: a comparative analysis of China and India. Energy Policy, 42, 450-460 https://doi.org/10.1016/j.enpol.2011.12.010

Lan, J., Kakinaka, M., \& Huang, X. (2012). Foreign direct investment, human capital and 492 environmental pollution in China. Environmental and Resource Economics, 51, 255-275 https://doi.org/10.1007/s10640-011-9498-2

494 Luqman, M., Ahmad, N. and Bakhsh, K. (2019). Nuclear energy, renewable energy and 495 economic growth in Pakistan: Evidence from non-linear autoregressive distributed lag model. Renewable Energy, 139, 139, $\quad 1299-1309$ https://doi.org/10.1016/j.renene.2019.03.008

Ma, X.-W., Ye, Y., Shi, X.-Q., \& Zou, L.-L. (2016). Decoupling economic growth from CO2 emissions: A decomposition analysis of China's household energy consumption. Advances in Climate Change Research, 7, 192-200 https://doi.org/10.1016/0304-3932(88)90168-7

Mahmood, H., \& Chaudhary, A. (2012). FDI, population density and carbon dioxide emissions: A case study of Pakistan. Iranica Journal of Energy \& Environment, 3, 354-360 https://doi.org/10.1016/j.accre.2016.09.004

Nadeem, A. M., Ali, T., Khan, M. T., \& Guo, Z. (2020). Relationship between inward FDI and environmental degradation for Pakistan: an exploration of pollution haven hypothesis through ARDL approach. Environmental Science and Pollution Research,https://doi.org/10.5829/idosi.ijee.2012.03.04.10 
509 Nasir, M., \& Rehman, F. U. (2011). Environmental Kuznets curve for carbon emissions 510 in Pakistan: an empirical investigation. Energy Policy, 39, 1857-1864 $511 \quad$ https://doi.org/10.1016/j.enpol.2011.01.025

512 Nathaniel, S., Nwodo, O., Sharma, G., \& Shah, M. (2020). Renewable energy, 513 urbanization, and ecological footprint linkage in CIVETS. Environmental Science 514 and Pollution Researchhttps://doi.org/10.1007/s11356-020-08466-0

515 Nguyen, T. T., Pham, T. A. T., \& Tram, H. T. X. (2020). Role of information and Management, 261, 110162 https://doi.org/10.1016/j.jenvman.2020.110162

519 Nordhaus, W. D. (2010). Economic aspects of global warming in a post-Copenhagen environment. Proceedings of the National Academy of Sciences, 107, 1172111726 https://doi.org/10.1073/pnas.1005985107

522 Omri, A., \& Kahouli, B. (2014). Causal relationships between energy consumption, foreign direct investment and economic growth: Fresh evidence from dynamic

526 Omri, A., Nguyen, D. K., \& Rault, C. (2014). Causal interactions between CO2 527 emissions, FDI, and economic growth: Evidence from dynamic simultaneous528 equation models. Economic Modelling, $\quad 42, \quad 382-389$ 529 https://doi.org/10.1016/j.econmod.2014.07.026 
530 Pao, H.-T., \& Tsai, C.-M. (2010). CO2 emissions, energy consumption and economic

531

532

533

534

535

536

537

538

539

540

541

542

543

544

545

546

547

548

549

550

551 growth in BRIC countries. Energy Policy, 38, 7850-7860 https://doi.org/10.1016/j.enpol.2010.08.045

Ramakrishnan, S., Hishan, S. S., Nabi, A. A., Arshad, Z., Kanjanapathy, M., Zaman, K., \& Khan, F. (2016). An interactive environmental model for economic growth: evidence from a panel of countries. Environmental Science and Pollution Research, 23, 14567-14579 https://doi.org/10.1007/s11356-016-6647-8

Robert, L. (1988). On the mechanics of economic development. Journal of Monetary Economics, 22, 3-42 https://doi.org/10.1016/0304-3932(88)90168-7

Romer, P. M. (1990). Endogenous technological change. Journal of political Economy, 98, S71-S102 https://doi.org/10.1086/261725

Ru, M., Shindell, D. T., Seltzer, K. M., Tao, S., \& Zhong, Q. (2018). The long-term relationship between emissions and economic growth for $\mathrm{SO} 2, \mathrm{CO} 2$, and $\mathrm{BC}$. Environmental Research Letters, 13, 124021 https://doi.org/10.1088/17489326/aaece2

Saboori, B., Sulaiman, J., \& Mohd, S. (2012). Economic growth and CO2 emissions in Malaysia: a cointegration analysis of the environmental Kuznets curve. Energy Policy, 51, 184-191 https://doi.org/10.1016/j.enpol.2012.08.065

Saidi, K., \& Mbarek, M. B. (2016). Nuclear energy, renewable energy, CO2 emissions, and economic growth for nine developed countries: Evidence from panel Granger causality tests. Progress in Nuclear Energy, 88, 364-374 https://doi.org/10.1016/j.pnucene.2016.01.018 
552 Salahuddin, M., Alam, K., Ozturk, I., \& Sohag, K. (2018). The effects of electricity

553

554

555

556

557

558

559

560

561

562

563

564

565

566

567

568

569

570

571

572

573

574

consumption, economic growth, financial development and foreign direct investment on $\mathrm{CO} 2$ emissions in Kuwait. Renewable and Sustainable Energy Reviews, 81, 2002-2010 https://doi.org/10.1016/j.rser.2017.06.009

Shahbaz, M., Haouas, I., \& Van Hoang, T. H. (2019). Economic growth and environmental degradation in Vietnam: Is the environmental Kuznets curve a complete picture? Emerging Markets Review, 38, 197-218 https://doi.org/10.1016/j.ememar.2018.12.006

Shahbaz, M., Nasir, M. A., \& Roubaud, D. (2018). Environmental degradation in France: the effects of FDI, financial development, and energy innovations. Energy Economics, 74, 843-857 https://doi.org/10.1016/j.eneco.2018.07.020

Shahbaz, M., Nasreen, S., Abbas, F., \& Anis, O. (2015). Does foreign direct investment impede environmental quality in high-, middle-, and low-income countries? Energy Economics, 51, 275-287 https://doi.org/10.1016/j.eneco.2015.06.014

Shahbaz, M., \& Sinha, A. (2019). Environmental Kuznets curve for CO2 emissions: a literature survey. Journal of Economic Studies, https://doi.org/10.1108/JES-092017-0249

Soytas, U., \& Sari, R. (2009). Energy consumption, economic growth, and carbon emissions: challenges faced by an EU candidate member. Ecological Economics, 68, 1667-1675 https://doi.org/10.1016/j.ecolecon.2007.06.014

Stern, D. I., \& van Dijk, J. (2017). Economic growth and global particulate pollution concentrations. Environmental Economics and Policy Studies, 142, 391-406 https://doi.org/10.1007/s10018-016-0148-3 
575 Tang, C. F., \& Tan, B. W. (2015). The impact of energy consumption, income and 576 foreign direct investment on carbon dioxide emissions in Vietnam. Energy, 79, 577 447-454 https://doi.org/10.1016/j.energy.2014.11.033

578 Tsang, E. W., \& Yip, P. S. (2007). Economic distance and the survival of foreign direct 579 investments. Academy of Management Journal, 50, 1156-1168 https://doi.org/10.2307/20159917

581 Udemba, E. N., Magazzino, C., \& Bekun, F. V. (2020). Modeling the nexus between pollutant emission, energy consumption, foreign direct investment, and economic growth: new insights from China. Environmental Science and Pollution Research, https://doi.org/10.1007/s11356-020-08180-x

Wang, S., Zhou, C., Li, G., \& Feng, K. (2016). CO2, economic growth, and energy consumption in China's provinces: investigating the spatiotemporal and econometric characteristics of China's CO2 emissions. Ecological Indicators, 69, 184-195 https://doi.org/10.1016/j.ecolind.2016.04.022

Wang, Y., Han, R., \& Kubota, J. (2016). Is there an environmental Kuznets curve for SO2 emissions? A semi-parametric panel data analysis for China. Renewable and Sustainable Energy Reviews, 54 $1182-1188$ https://doi.org/10.1016/j.rser.2015.10.143

Wang, Z., Asghar, M. M., Zaidi, S. A. H., \& Wang, B. (2019). Dynamic linkages among CO 2 emissions, health expenditures, and economic growth: empirical evidence from Pakistan. Environmental Science and Pollution Research, 26, 15285-15299 https://doi.org/10.1007/s11356-019-04876-X 
597 Yang, J., \& Shan, H. (2019). Identifying Driving Factors of Jiangsu's Regional Sulfur 598 Dioxide Emissions: A Generalized Divisia Index Method. International Journal of Environmental Research and Public Health, 16, 4004 https://doi.org/10.3390/ijerph16204004

601 Yasmeen, H., Wang, Y., Zameer, H., \& Solangi, Y. A. (2020). Decomposing factors 602

613 Zafar, M. W., Shahbaz, M., Hou, F., \& Sinha, A. (2019). From nonrenewable to 614 renewable energy and its impact on economic growth: the role of research \& 615 affecting CO 2 emissions in Pakistan: insights from LMDI decomposition approach. Environmental Science and Pollution Research, 27, 3113-3123 https://doi.org/10.1007/s11356-019-07187-3

Yavuz, N. Ç. (2014). CO2 emission, energy consumption, and economic growth for Turkey: Evidence from a cointegration test with a structural break. Energy Sources, Part B: Economics, Planning, and Policy, , 229-235 https://doi.org/10.1080/15567249.2011.567222

Yilanci, V., Bozoklu, S., \& Gorus, M. S. (2020). Are BRICS countries pollution havens? Evidence from a Bootstrap ARDL Bounds testing approach with a Fourier function. Sustainable Cities and Society, https://doi.org/10.1016/j.scs.2020.102035 development expenditures in Asia-Pacific Economic Cooperation countries. Journal of Cleaner Production, 212, 1166-1178 https://doi.org/10.1016/j.jclepro.2018.12.081 
618 Zeng, K., \& Eastin, J. (2012). Do developing countries invest up? The environmental 619 effects of foreign direct investment from less-developed countries. World 620 Development, 40, 2221-2233 https://doi.org/10.1016/j.worlddev.2012.03.008

621 Zhang, C., \& Zhou, X. (2016). Does foreign direct investment lead to lower CO2 622 emissions? Evidence from a regional analysis in China. Renewable and Sustainable Energy Reviews, 58,

943-951

624 https://doi.org/10.1016/j.rser.2015.12.226

625 Zhang, J., Wu, G., \& Zhang, J. (2004). Estimation on China’s regional physical capital 626 stock: 1952-2000'. Economic Research, 10, 35-45 https://doi.org/10.1080/14765280802028302

628 Zhang, Y.-J. (2011). The impact of financial development on carbon emissions: An 629 empirical analysis in China. Energy Policy, 39, 2197-2203 https://doi.org/10.1016/j.enpol.2011.02.026

631 Zhao, X., Deng, C., Huang, X., \& Kwan, M.-P. (2017). Driving forces and the spatial patterns of industrial sulfur dioxide discharge in China. Science of the Total Environment, 577, 279-288 https://doi.org/10.1016/j.scitotenv.2016.10.183

634 Zhu, L., Gan, Q., Liu, Y., \& Yan, Z. (2017). The impact of foreign direct investment on 635 SO2 emissions in the Beijing-Tianjin-Hebei region: A spatial econometric 636 analysis. Journal of Cleaner Production, 166, $189-196$ https://doi.org/10.1016/j.jclepro.2017.08.032

638

639

640 
641 Fig. 1 Sources of SO2 emission

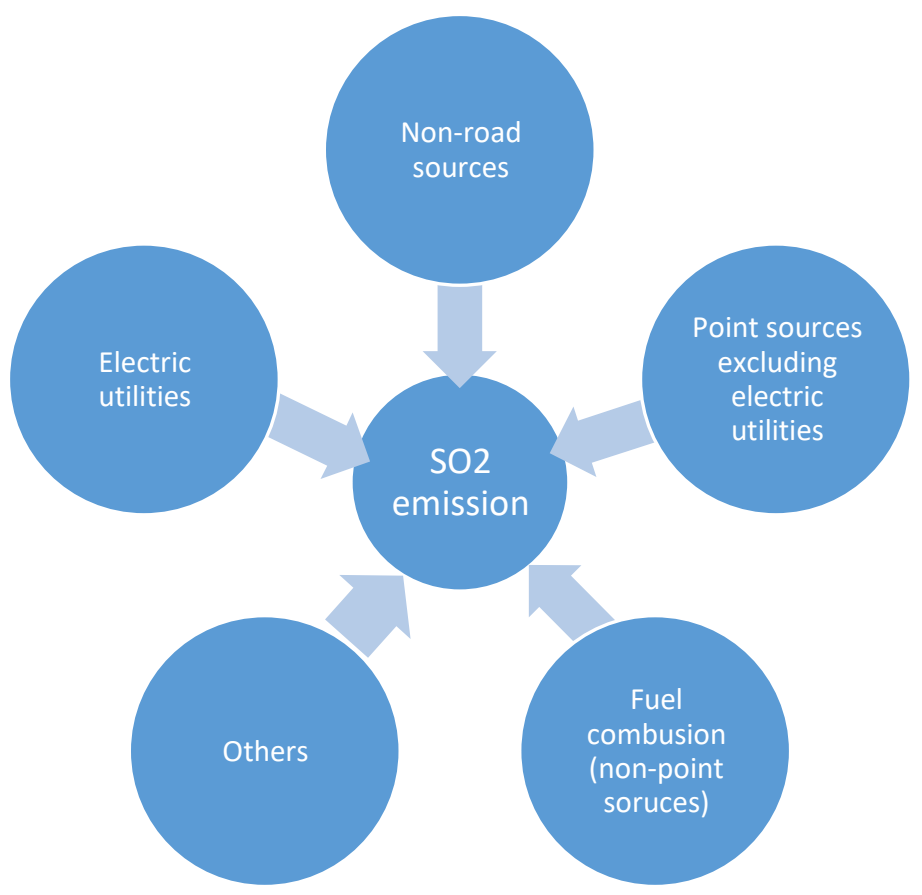


643 Fig. 2 Flow diagram of empirical method

644

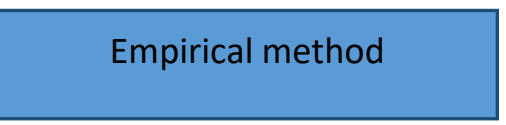

\section{Empirical contents}

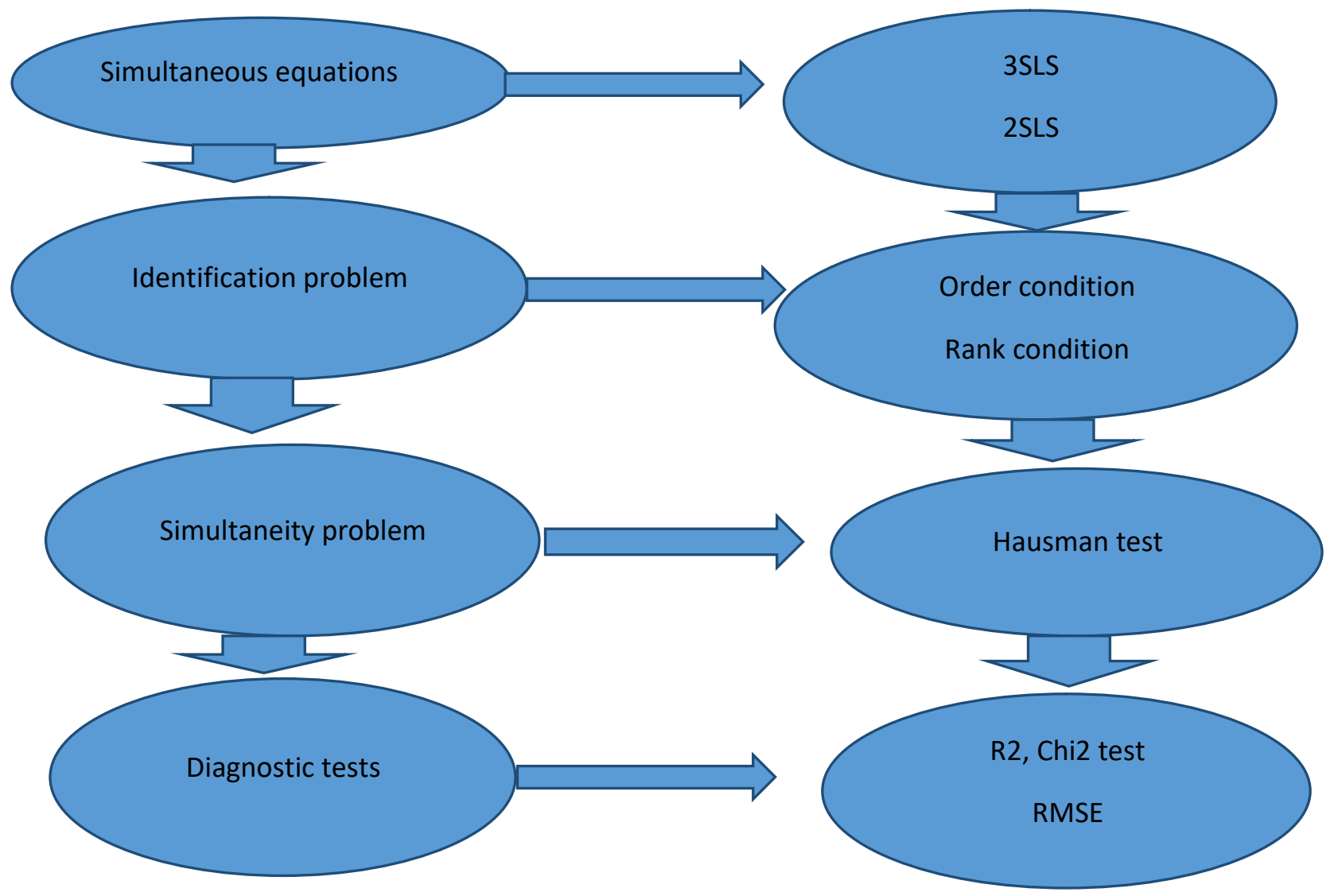


645 Table 1. Definition of variables and the data sources

\begin{tabular}{llll}
\hline Variables & Unit & Definitions & Source \\
\hline GDP & US\$ Million & Gross domestic product & SBP \\
Energy & $\mathrm{kt}$ & Total energy use equitant to oil & WDI \\
Capital & Million US\$ & Total gross fixed capital formation & SBP \\
Investment & US\$ Million & Gross total investment & SBP \\
$\mathrm{SO}_{2}$ & Giga & Total SO $\mathrm{S}_{2}$ emission & WDI \\
Capital intensity & US\$ Million & Total capital stock divided by labor & SBP \\
& & force & \\
Industrialization & $\%$ GDP & Industrial value added scaled by GDP & Index Mundi \\
FDI & US\$ million & Foreign direct investment inflow & SBP \\
Pop. Density & Number & Population per square km & WDI \\
\hline
\end{tabular}

646

647 
649 Table 2: Results for scale effect

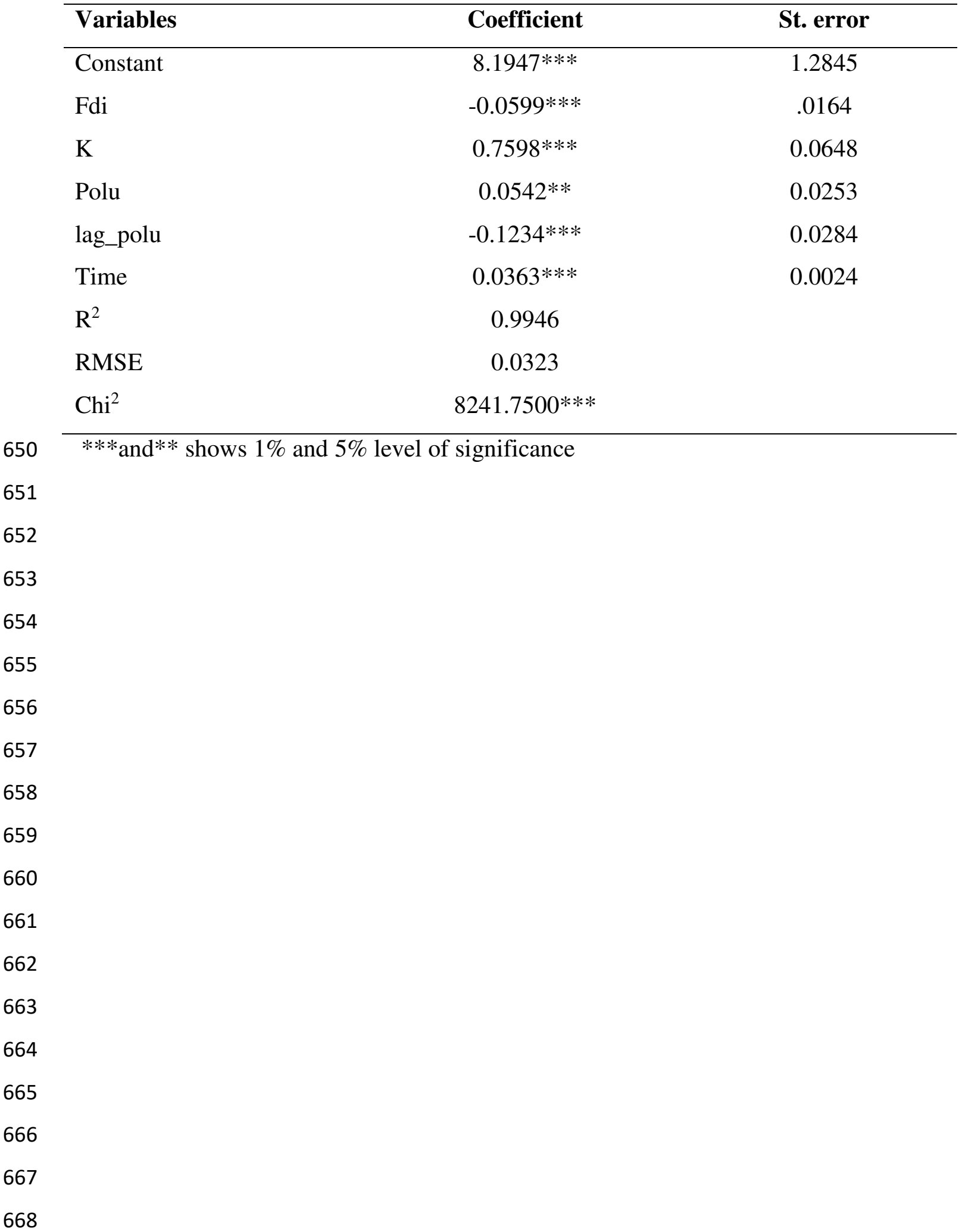


670 Table 3. Estimates of capital accumulation effect of FDI

\begin{tabular}{|c|c|c|c|}
\hline & Variables & Coefficient & St. error \\
\hline & Constant & $-10.2678 * * *$ & 2.5771 \\
\hline & Fdi & $0.0904 * * *$ & 0.0186 \\
\hline & $\operatorname{gdp}_{\mathrm{t}-1}$ & $0.75876^{* * *}$ & 0.2573 \\
\hline & $\operatorname{gdp}_{\mathrm{t}-2}$ & $0.5489 * *$ & 0.2397 \\
\hline & Time & $-0.0429 * * *$ & 0.0055 \\
\hline & $\mathrm{R}^{2}$ & 0.9828 & \\
\hline & RMSE & 0.0433 & \\
\hline & $\mathrm{Chi}^{2}$ & $2152.9300 * * *$ & \\
\hline 671 & \multicolumn{3}{|c|}{$* * *$ and $* *$ are level of significance at $1 \%$ and $5 \%$} \\
\hline \multicolumn{4}{|l|}{672} \\
\hline \multicolumn{4}{|l|}{673} \\
\hline \multicolumn{4}{|l|}{674} \\
\hline \multicolumn{4}{|c|}{675} \\
\hline \multicolumn{4}{|c|}{676} \\
\hline \multicolumn{4}{|l|}{677} \\
\hline \multicolumn{4}{|c|}{678} \\
\hline \multicolumn{4}{|c|}{679} \\
\hline \multicolumn{4}{|c|}{680} \\
\hline \multicolumn{4}{|l|}{681} \\
\hline \multicolumn{4}{|l|}{682} \\
\hline \multicolumn{4}{|l|}{683} \\
\hline \multicolumn{4}{|l|}{684} \\
\hline \multicolumn{4}{|l|}{685} \\
\hline \multicolumn{4}{|l|}{686} \\
\hline \multicolumn{4}{|l|}{687} \\
\hline \multicolumn{4}{|l|}{688} \\
\hline 689 & & & \\
\hline 690 & & & \\
\hline
\end{tabular}


691 Table 4: Estimates of the technique effect

\begin{tabular}{lcc}
\hline Variables & Coefficient & St. error \\
\hline Constant & 25.4240 & 18.8107 \\
Fdi & $0.5375^{* * *}$ & 0.1797 \\
Gdp & $-9.3192^{* * *}$ & 1.7978 \\
Pd & $30.5398^{* * *}$ & 6.7529 \\
Energy & $6.5854^{* * *}$ & 2.0371 \\
Time & $-0.5916^{* * *}$ & 0.1360 \\
$\mathrm{R}^{2}$ & 0.4329 & \\
RMSE & 0.2220 & \\
Chi $^{2}$ & $85.3300^{* * *}$ & \\
\hline
\end{tabular}


694 Table 5: Estimates of composition effect

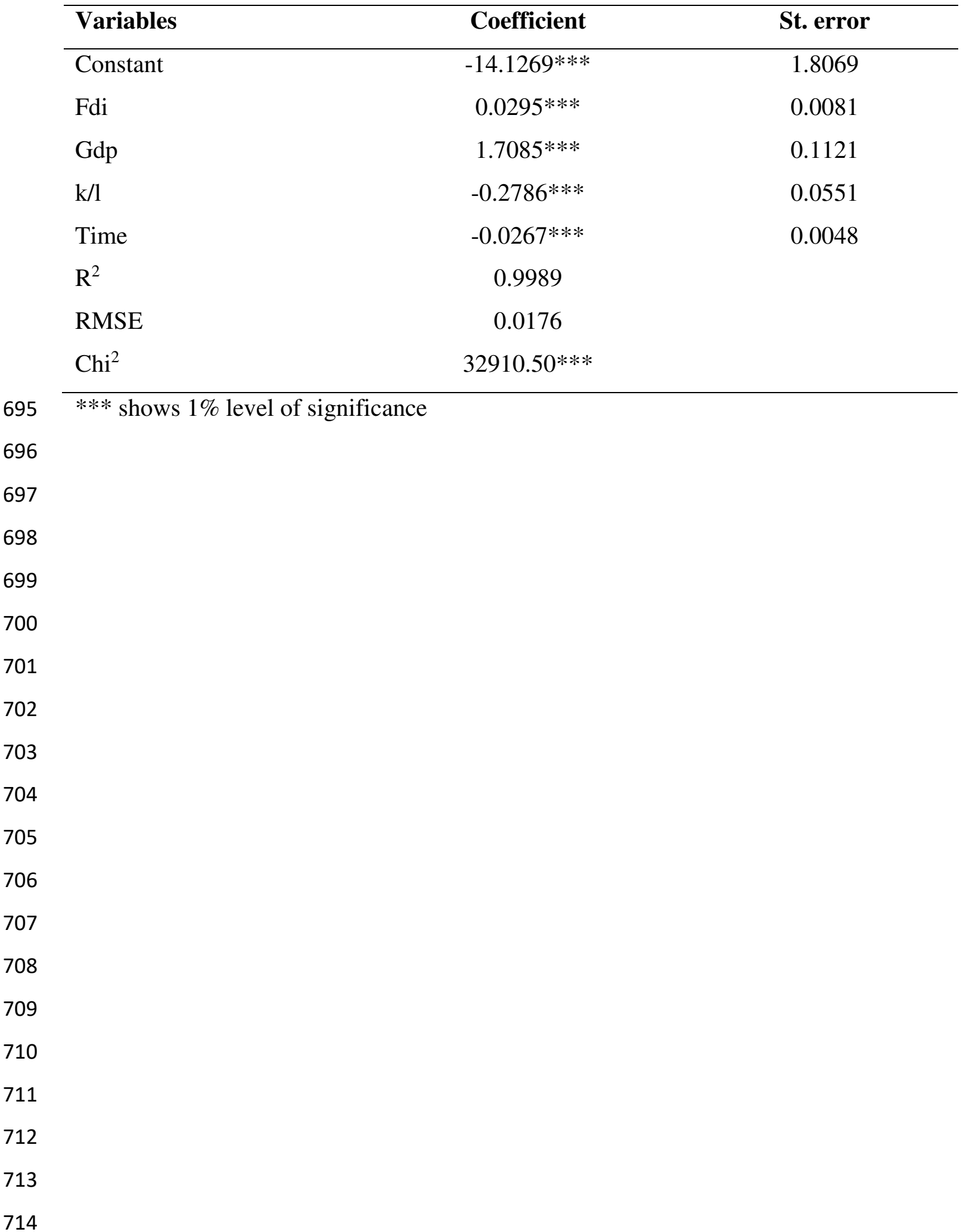


716 Table 6: Estimates of FDIdeterminants

\begin{tabular}{lcc}
\hline Variables & Coefficient & St. error \\
\hline Constant & $-39.5710^{*}$ & 22.8250 \\
ddi $_{\mathrm{t}-1}$ & $0.3450 * *$ & 0.1423 \\
ind $_{\mathrm{t}-1}$ & -1.1389 & 1.5859 \\
inv $_{\mathrm{t}-1}$ & $3.4730 * * *$ & 1.4164 \\
Polu & $-0.7443 * *$ & 0.3302 \\
Time & 0.0971 & 0.0637 \\
$\mathrm{RMSE}^{2}$ & 0.3920 & \\
$\mathrm{R}^{2}$ & 0.9197 & \\
$\mathrm{Chi}^{2}$ & $404.8800 * * *$ & \\
\hline$* * * * *$ and $*$ are level of significance at $1 \%, 5 \%$ and $10 \%$ respectively &
\end{tabular}


738 Table 7. Effects of FDI on pollution emission

\begin{tabular}{lc}
\hline Variables & Effects of FDI on SO2 emission \\
\hline Total effect & -0.5393 \\
Scale effect & 0.1287 \\
Technique effect & -0.6622 \\
Composition effect & 0.1610 \\
\hline
\end{tabular}

739

740

741

742

743

744

745

746

747

748

749

750

751

752

753

754

755

756

757

758

759

760

761 
763 Appendix A. Glossary of notations used in system of equations

\begin{tabular}{ll}
\hline Notations & \multicolumn{1}{c}{ Description } \\
\hline Fdi & fdi stands for foreign direct investment. An individual or a company \\
& residing in one country makes investment in another country is \\
known as FDI. It can be in the form of establishing business \\
operations or buying assets in the target country. \\
inv stands for investment. It is the investment made by public and \\
private sources in a country. This is used to attract FDI in the country. \\
gdp shows gross domestic product. It is the value of all final goods \\
and services produced in a country during the specific period of time \\
Gdp & $\begin{array}{l}\text { like during one year. } \\
\text { polu indicates SO2 emission. This greenhouse gas is a colorless and it }\end{array}$ \\
is emitted from burning of oil and coal and industrial processes \\
Pol & Entaining sulfur. \\
Eng & resources to be used for heating, cooling and lighting purposes or for \\
running machines. & $\mathrm{k}$ shows gross fixed capital formation. It shows availability of \\
building, machinery, equipment, etc. to be used in the production \\
process. It is among factors of production. \\
It represents capital intensity. It shows the amount of capital in \\
relation to other factors of production like labor, land, etc. \\
Ind
\end{tabular}




\section{Declarations}

768 Ethics approval

769 Not applicable

770 Consent to participate

771 Not applicable

772 Consent for publication

773 Not applicable

774 Competing interests

775 The authors declare that they have no competing interests

776 Authors' contributions

$777 \mathrm{~KB}$ interpreted the data, reviewed the literature and was the major contributor in writing

778 the manuscript. TA1 contributed in the research article in collecting data from different

779 sources, and reviewed the literature. Reviewing the final manuscript was done by TA2.

780 QA contributed in modeling and data analyzing.

$781 \quad$ Funding

782 Not applicable

783 Availability of data and materials

784 The datasets used and /or analyzed during the current study are available from the 785 corresponding author on reasonable request. 
Figures

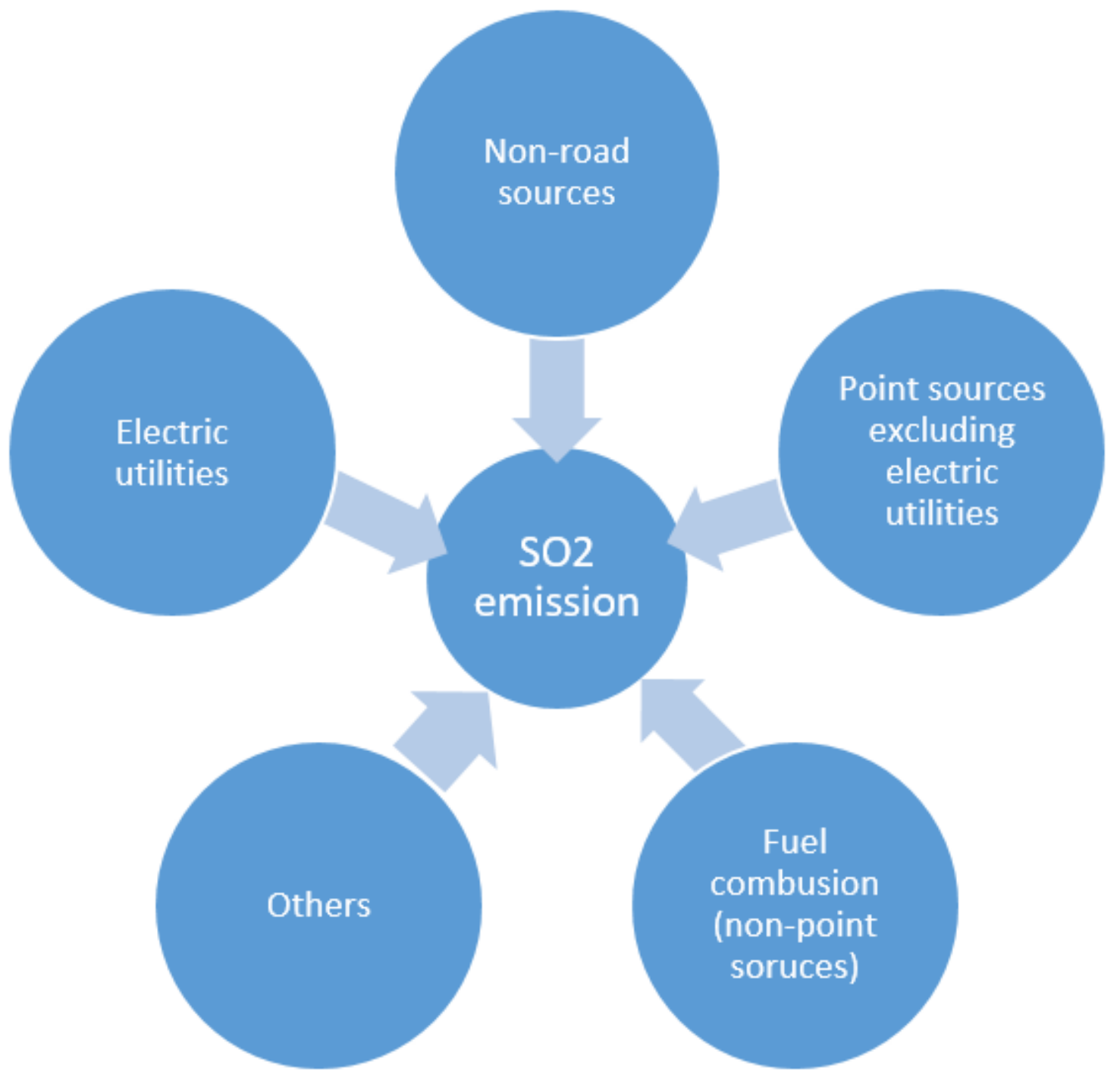

Figure 1

Sources of SO2 emission 


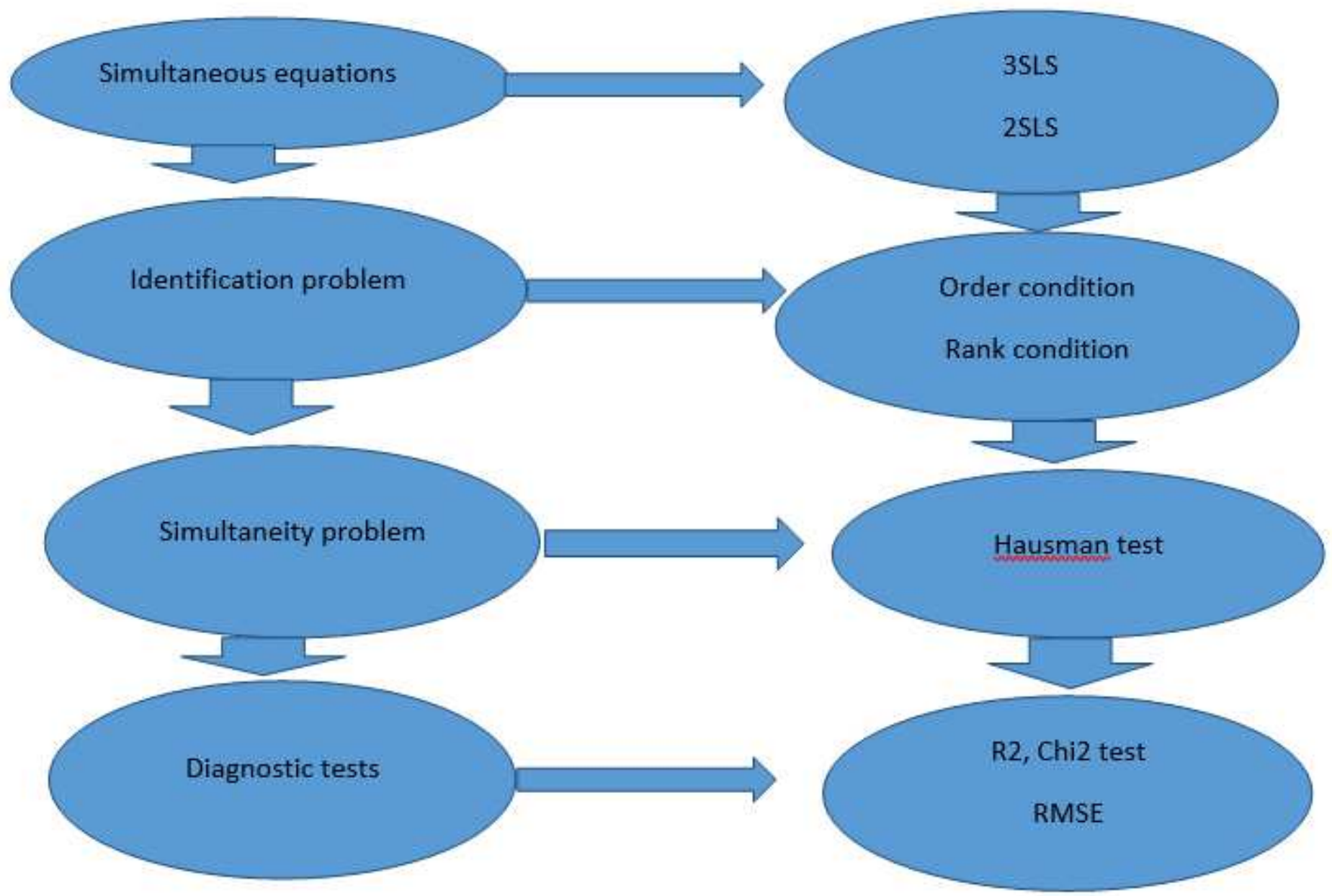

Figure 2

Flow diagram of empirical method 